\title{
How Do Import Refusals for Pathogen Violations Respond to a Recession?
}

\author{
M. Taylor Rhodes ${ }^{1^{*}}$
}

Oregon State University, School of Public Policy, 318 Bexell Hall, Corvallis, OR 97331

\section{ABSTRACT}

Using publicly available import refusal data, this paper examines the extent to which an economic recession affects import refusals for pathogen violations-shipments that appear to violate the laws enforced by the United States (U.S.) Food and Drug Administration (FDA) on adulterated products. Statistically significant differences in the average share of pathogen violations suggest that changes in import refusals by pathogen type were associated with the 2007 to 2009 U.S. recession. Compared to averages before 2007, the average share of pathogen violations increased by 13.4 percentage points for Salmonella, decreased by 8.4 percentage points for Listeria and decreased by 2.7 percentage points for Histamine. While this could have been caused by changes in inspection or by changes in the quality of the food imported the results nonetheless suggest that aligning additional inspection resources immediately following macroeconomic slowdowns towards shipments more susceptible to Salmonella may help minimize the risk of foodborne illness from imported products.

Keywords: Foodborne illness, import refusals, pathogens, recessions

* Author for correspondence. Tel: (541) 737-2811; Fax: (541) 737-2289; E-mail:

Taylor.Rhodes@oregonstate.edu 


\section{INTRODUCTION}

During the 2007 to 2009 recession, U.S. total imports declined by 34\% and notable subcategories like consumer goods and agricultural products declined by $15 \%$ and $9 \%$, respectively (Levchenko et al. 2010). Additionally, the volume of U.S. food imports per U.S. person declined in 2008 until 2009. Total imports from Mexico, India, and China declined by 29\%, 21\%, and 16\%, respectively (Levchenko et al. 2010). These three countries have also been shown to have the most import refusals (Bovay, 2016).

This paper uses publicly available import refusal data from the FDA to detect changes in the share of pathogen violations by specific pathogen and product type before and after the 2007 to 2009 U.S. recession (FDA, 2015). Previous research has shown an association between rising imports and higher shares of import refusals by industry type (Brooks et al. 2009); hence, there is a potential that time periods correlated with declining food imports could be associated with lower shares of import refusals.

Pathogen refusals, meaning import shipments that appear to violate the laws enforced by the FDA on adulterated products, are of public-health interest because pathogen-contaminated food can result in illnesses ranging from nausea, vomiting, and diarrhea to renal failure, paralysis, and death (Hoffmann et al. 2012). In the U.S., foodborne illnesses from major pathogens cost an estimated \$14 billion per year and may result in over 50,000 hospitalizations and up to 1,390 deaths per year. Particularly at-risk populations include infants, pregnant and nursing women, and people aged 65 or older. Identifying adulterants in imported foods and refusing contaminated shipments help minimize the risk of foodborne illness from foreign products and is essential towards keeping U.S. consumers safe.

Previous research using FDA import refusal data has not focused on describing product-level changes, but rather has focused on describing trends in import refusals by violation type (Buzby et al. 2008 and Bovay 2016), by industry categories (Buzby et al. 2008 and Bovay 2016) and by country of origin (Buzby et al. 2009, Brooks et al. 2009, Gale et al. 2009, Buzby et al. 2010 and Bovay 2016). The objective of this paper is to examine if the 2007 to 2009 recession altered import refusals for pathogens known to cause foodborne illness and to identify which products account for any detected changes. If product-level changes can be detected, then targeting the specific products following a recession may reduce the likelihood that tainted food enters the U.S. food supply, thereby reducing the risk of foodborne illness. But more generally, achieving a better understanding as to which products most contribute to pathogen refusals would benefit inspection efforts and likely help minimize the risk of foodborne illness from imported products.

\section{MATERIALS AND METHODS}

The FDA physically examines approximately 1 to 2\% of food imports and since 2009 electronically screens import entries to assess risk using an automated system called Predictive Risk-based Evaluation for Dynamic Import Compliance Targeting (PREDICT) (Bovay 2016 and Johnson 2016). Data on import refusals are made available online by the FDA with entries that contain a violation code, product description code, industry, and country of origin (FDA, 2015). In the data, recorded pathogens for import refusals include various bacteria (Salmonella, Shigella, Vibrio, E. coli O157, and Listeria), a virus (Hepatitis A) and some toxins (Aflatoxin, Biotoxin, Histamine, and Patulin).

In the present study, to detect annual changes, violations for each type of pathogen from the import refusal data were calculated for each year in the data. Averages were then calculated to 
compare results before (2002 to 2006), during (2007 to 2009) and after (2010 to 2013) the recession.

To detect the magnitude of changes before and after the recession, annual pathogen shares for each type of pathogen, meaning the number of violations for a specific pathogen normalized by the total number of violations across all pathogens, were averaged across all years before and after the recession period. This segmentation helps to quantify by how much and in what direction pathogen violations changed in response to the recession after normalizing by the total number of pathogen violations.

To identify which specific products account for detected changes in pathogen violations, pathogen shares were examined by product type. Specifically, statistical differences at the $10 \%$ level or better in average annual pathogen shares before 2007 and after 2009 for each pathogen type were analyzed by each product type. These differences help to determine if time periods correlated with declining food imports were associated with changes in the share of import refusals for pathogen violations and by which product.

Product descriptions in the import refusal data contained one word (e.g. Quail) or possibly multiple words (e.g. Oriental Noodles (flavored with Shrimp, Chicken, Beef, Lobster, Crab, Plain, Etc.)).Without any edits, there were 4,420 product type entries. This total ignores spelling errors of otherwise identical products - the most common being capitalization (e.g. CARP versus carp versus Carp). Also, this total ignores similar products (e.g. Anchovy versus Anchovy, Cold Smoked, Fish; or, Sushi, raw versus Sushi, unspecified). After correcting capitalization errors and grouping by similar descriptions, 537 product-type identifiers were created and examined.

\section{RESULTS}

\section{Dynamic Changes in Pathogen Violations}

The annual number of pathogen violations from 2002 to 2013 for Salmonella, Listeria, Histamine, and all others are shown in Figure 1. Salmonella violations accounted for nearly $80 \%$ of all pathogen violations, followed by Listeria (11\%), Histamine (3\%), Aflatoxin (3\%) and [Other] Bacteria (2\%).

Averages for the years before (2002 to 2006), during (2007 to 2009) and after (2010 to 2013) the recession indicate the number of violations for Salmonella increased after the recession compared to before the recession. Before the recession, the average annual number of violations was 894. During the recession, this increased to 1,167 and after the recession, further to 1,517.

In contrast, violations for Listeria decreased after the recession compared to before the recession. Violations for Histamine decreased after the recession compared to before the recession.

The average number of violations for all other pathogens, including Aflatoxin, Bacteria, E. coli 0157, Shigella, "Diseased," Patulin, Vibrio, Hepatitis A, Biotoxin, and "Insanitary and Bovine Spongiform Encephalopathy (Insanitary BSE),” decreased after the recession compared to before the recession 

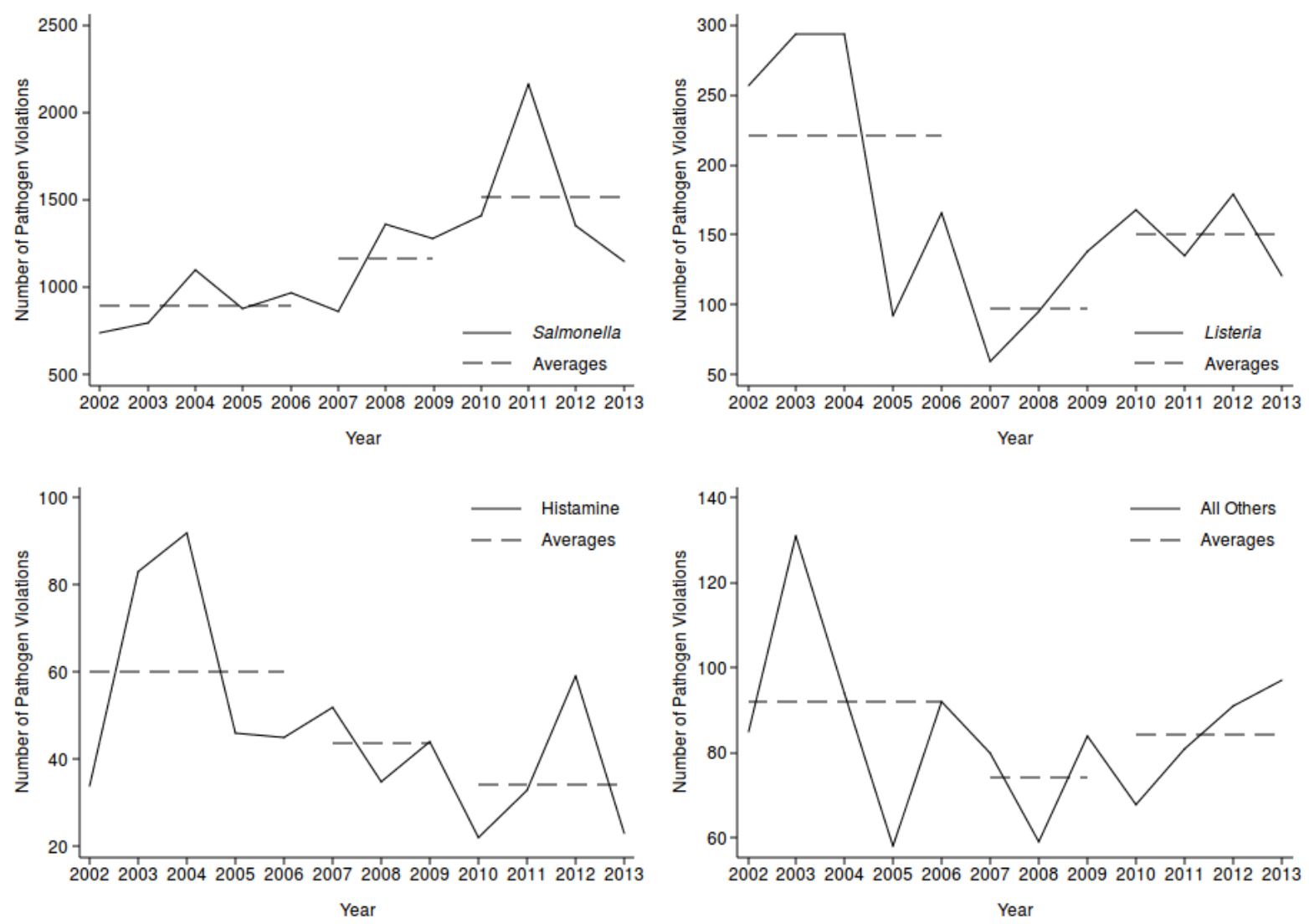

FIGURE 1: Solid lines indicate the number of pathogen violations by each listed pathogen. Dashed lines indicate the average number of pathogen violations for 2002 to 2006, 2007 to 2009 and 2010 to 2013. "All Others" indicate number of pathogen violations for Aflatoxin, Bacteria, E. coli 0157, Shigella, "Diseased,” Patulin, Vibrio, Hepatitis A, Biotoxin, and "Insanitary BSE.”

\section{Changes in the Share of Pathogen Violations: Pre-2007 vs. Post-2009}

The average annual pathogen share prior to 2007 and the average annual pathogen share after 2009 by pathogen type are shown in Figure 2. The average annual share of pathogen violations from Salmonella increased from $70.9 \%$ before the recession $84.3 \%$ afterwards, an increase of 13.4 percentage points $(\mathrm{p}=0.02)$. The average annual share of pathogen violations from Listeria was $17.2 \%$ prior to 2007 and $8.8 \%$ after 2009 , a decrease of 8.4 percentage points $(\mathrm{p}=0.04)$. Violations from Histamine was 4.6\% prior to 2007 and $1.96 \%$ after 2009, a decrease of 2.7 percentage points $(\mathrm{p}=0.02)$. For all other pathogen types, the average annual share did not statistically change. 

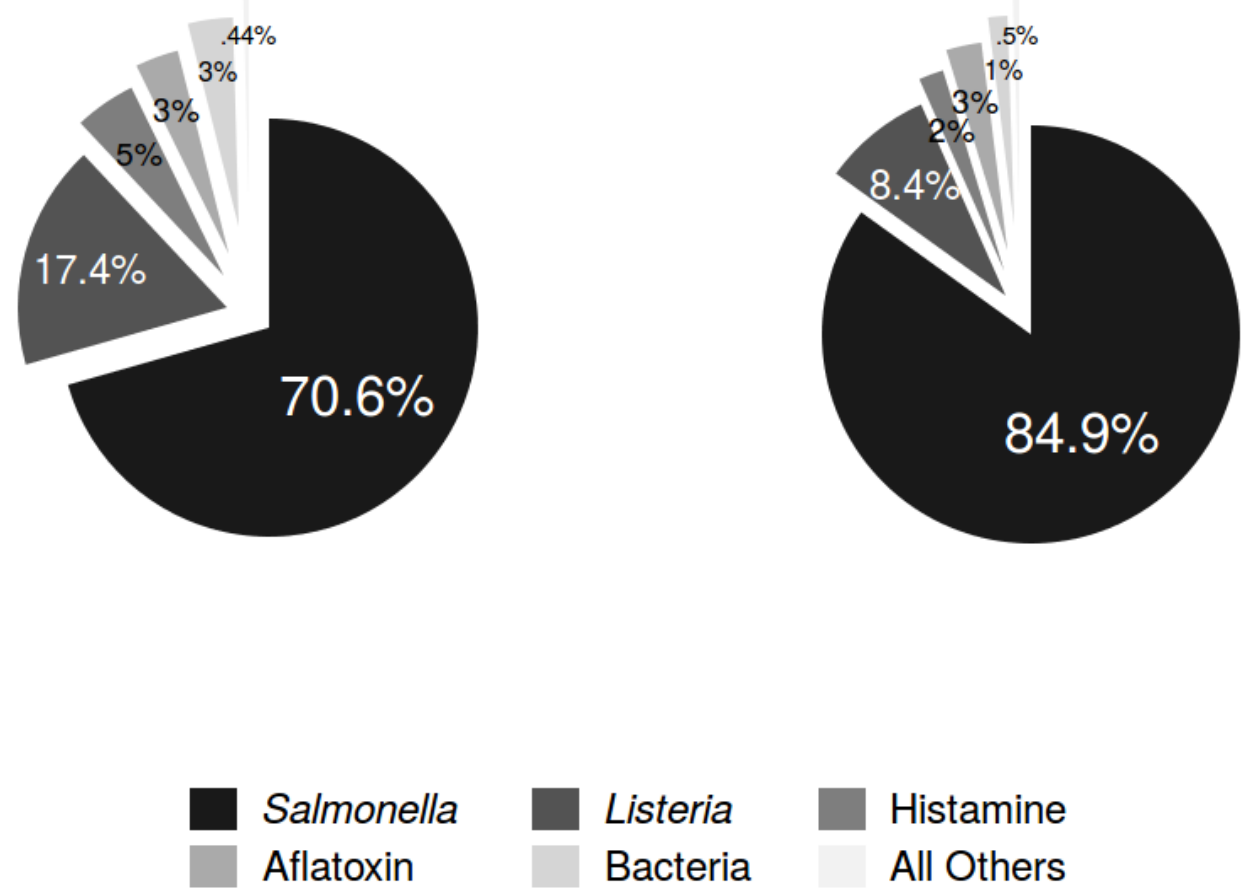

Histamine All Others

FIGURE 2: Average annual share (\%) of pathogen violations by type of pathogen. "All Others" includes E. coli 0157, Shigella, Diseased, Patulin, Vibrio, Hepatitis A, Biotoxin, and Insanitary BSE. Statistically significant differences at the 5\% level include: Salmonella (increase of 13.4 percentage points with $p$ value of 0.02 ), Listeria (decrease of 8.4 percentage points with $p$-value of 0.04 ), and Histamine (decrease of 2.7 percentage points with $p$-value of 0.02 ).

Next, the pathogen-level changes in Figure 2 were traced down to the product-level (over 527 product types) to identify the collection of products that account for the statistical differences presented in Figure 2. So, similar to the decision to keep a regressor, product-level findings at the $10 \%$ level or better are identifying the possible products types that most explain the observed pathogen changes in Salmonella, Listeria, and Histamine violations.

\section{Changes in Salmonella Violations}

The 13.4 percentage point increase in the average annual share of pathogen violations from Salmonella was decomposed by product type to potentially isolate the specific products most affected by the 2007 to 2009 recession. At the product-type level, the results for the 10 most positive and 10 most negative differences between the average annual share of pathogen violations from Salmonella prior to 2007 and after 2009 are shown in Figure 3.

For papaya products, it increased by 7.4 percentage points but was not statistically significant. For tuna products, it increased by 6.5 percentage points $(\mathrm{p}=0.01)$. For spice products, it increased by 5.1 percentage points $(\mathrm{p}=0.05)$. For capsicums, cucumber, tilapia, and cumin products, the 
average annual share of pathogen violations from Salmonella each increased by approximately 2 percentage points. The differences for capsicums and cumin were statistically significant at the $5 \%$ level but were not statistically significant for cucumber and tilapia.

For shrimp products, the average annual share of pathogen violations from Salmonella decreased by 12 percentage points $(\mathrm{p}=0.05)$. For lobster products, it decreased by 2 percentage points, a statistically significant difference at the $1 \%$ level. For crab products, it decreased by 1.4 percentage points, a statistically significant difference at the $5 \%$ level.

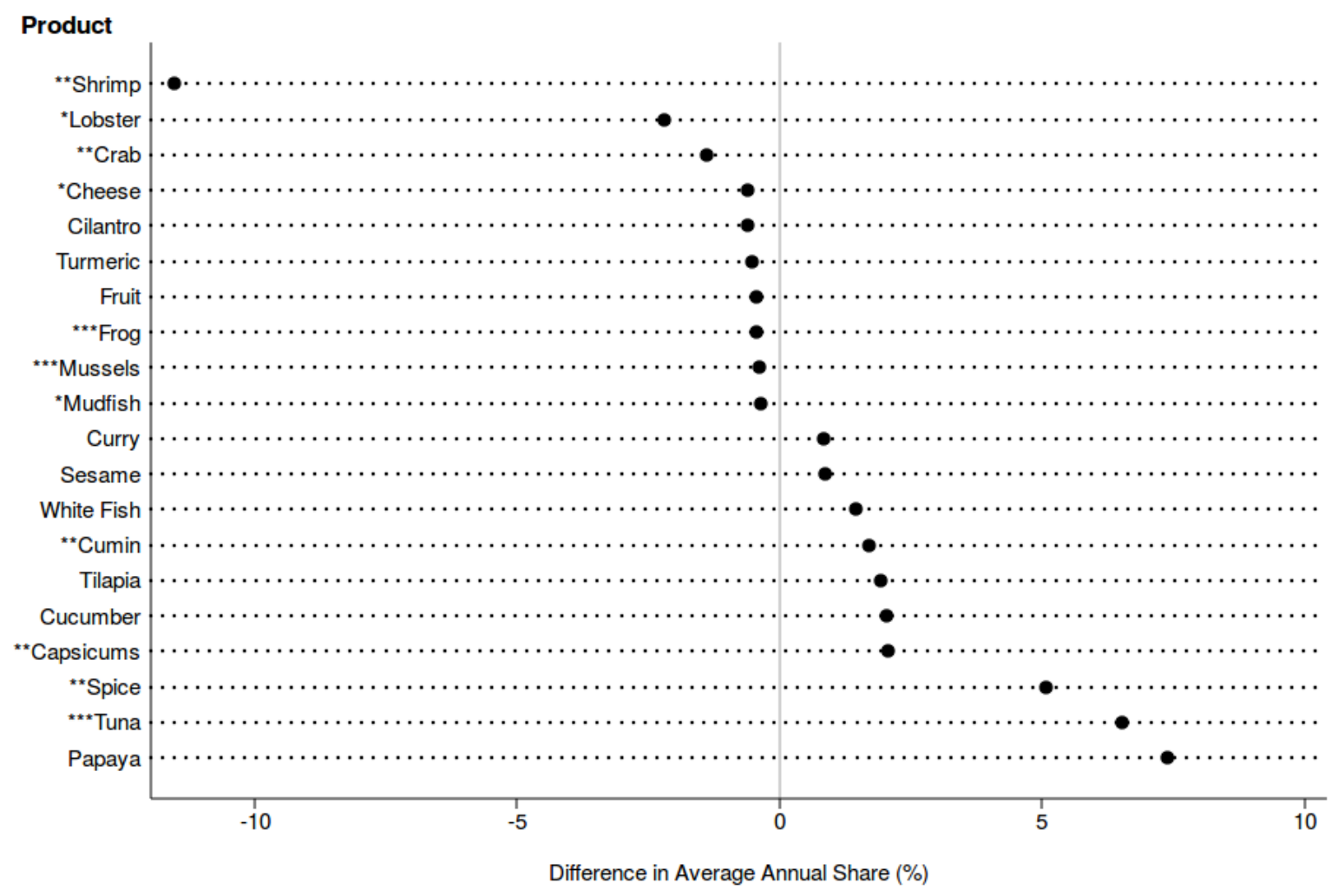

(2002 to 2006 vs 2010 to 2013)

FIGURE 3: Differences in average annual share (\%) of pathogen violations by product type from Salmonella. Dots $(\bullet)$ indicate the difference in average annual share of pathogen violations for Salmonella by product type between 2002 to 2006 and 2010 to 2013. The 10 most positive and 10 most negative differences are shown. Statistically significant differences: ${ }^{*} p$-value $<0.10,{ }^{* *} p$-value $<0.05$, and ${ }^{* * *} p$ value $<0.01$.

\section{Changes in Listeria Violations}

Next, the 8.4 percentage point decrease in the average annual share of pathogen violations from Listeria was decomposed by product type. At the product-type level, the results for the 10 most positive and 10 most negative differences between the average annual share of pathogen violations from Listeria prior to 2007 and after 2009 are shown in Figure 4.

For cheese products, the average annual share of pathogen violations from Listeria decreased by 5.5 percentage points, a statistically significant difference at the $1 \%$ level. For guacamole products, it decreased by 2.4 percentage points but was not statistically significant. For avocado 
products, it decreased by 0.7 percentage points but was not statistically significant. For shrimp products, it increased by $0.6 \%$, a statistically significant difference at the $10 \%$ level.

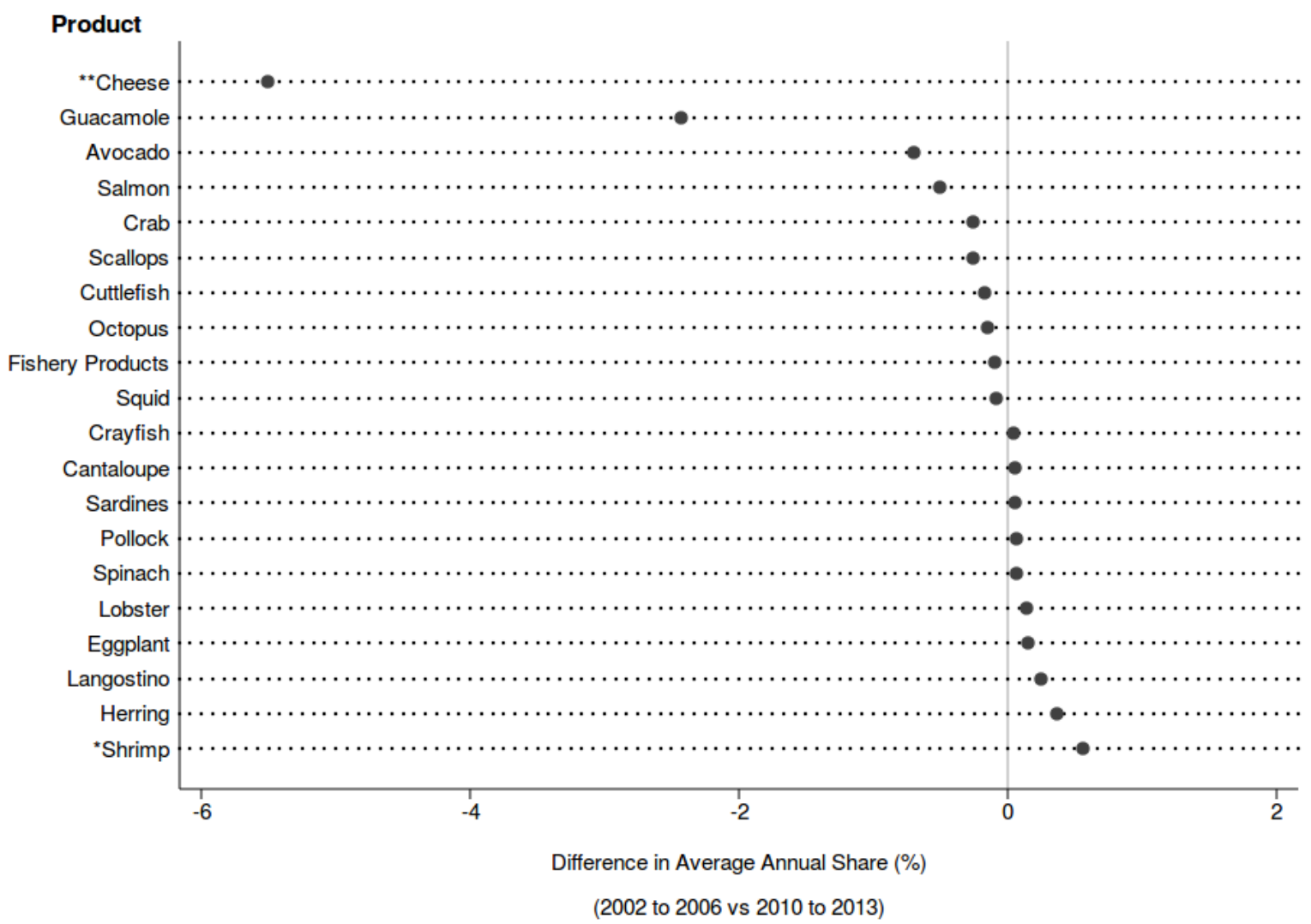

FIGURE 4: Difference in average annual share (\%) of pathogen violations by product type from Listeria. Dots $(\bullet)$ indicate the difference in average annual share of pathogen violations for Listeria by product type between 2002 to 2006 and 2010 to 2013. The 10 most positive and 10 most negative differences are shown. Statistically significant differences: ${ }^{*} p$-value $<0.10,{ }^{* *} p$-value $<0.05$, and ${ }^{* * *} p$-value $<0.01$.

\section{Changes in Histamine Violations}

The 2.7 percentage point decrease in the average annual share of pathogen violations from Histamine was decomposed by product type. At the product-type level, the results for the 5 most (and only) positive and 10 most negative differences between the average annual share of pathogen violations from Histamine prior to 2007 and after 2009 are in Figure 5.

For tuna products, the average annual share of pathogen violations from Histamine decreased by 1.4 percentage points, a statistically significant difference at the $10 \%$ level. For Mahi products (dolphin flesh), it decreased by 0.8 percentage points, a statistically significant difference at the $10 \%$ level. For escolar products, it decreased by 0.2 percentage points, a statistically significant difference at the $10 \%$ level. 


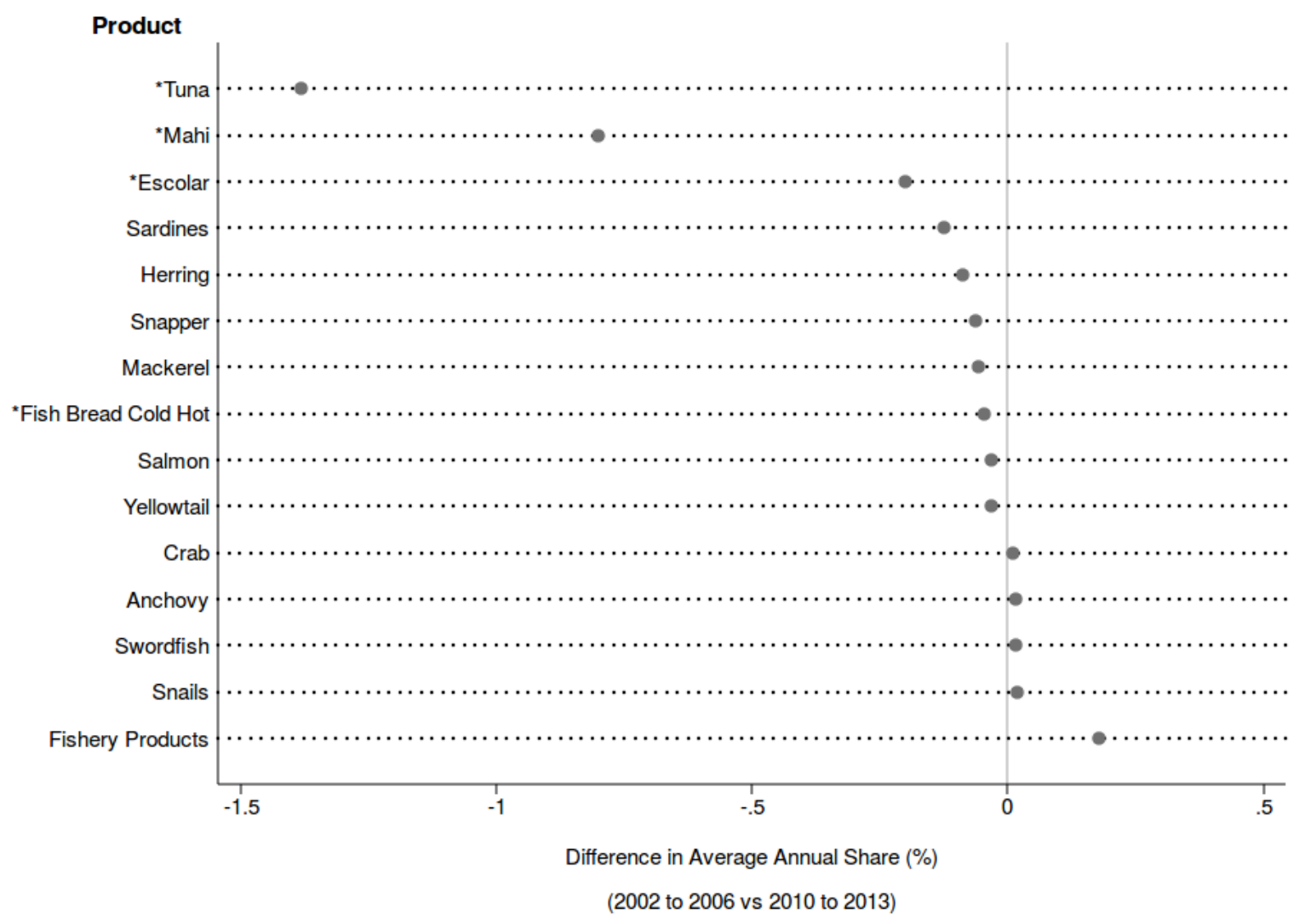

FIGURE 5: Difference in average annual share (\%) of pathogen violations by product type from Histamine. Dots $(\bullet)$ indicate the difference in average annual share of pathogen violations for Histamine by product type between 2002 to 2006 and 2010 to 2013. The 5 most (and only) positive and 10 most negative differences are shown. Statistically significant differences: $* p$-value $<0.10, * * p$-value $<0.05$, and $* * *$-value $<0.01$.

\section{DISCUSSION}

The 2007 to 2009 recession may have altered pathogen violation import refusals. Specifically, for the years prior (2002 to 2006), the average annual share of pathogen violations from Salmonella was $70.9 \%$. For the years after (2010 to 2013), the average increased to $84.3 \%$, a statistically significant increase of 13.4 percentage points. The main products contributing to this increase were papaya, tuna, and spice. Given these increases, aligning additional inspection efforts immediately following economic slowdowns for shipments more susceptible to Salmonella may help minimize the risk of foodborne illness from imported products.

In contrast to pathogen violations from Salmonella, the average annual share of pathogen violations from Listeria and Histamine declined by 8.4 and 2.7 percentage points, respectively, in the years after the recession (2010 to 2013) when compared to pre-recession years (2002 to 2006). For Listeria, the contributing products towards the decline were cheese, guacamole, and avocado products. For Histamine, the products that mostly contributed towards the decline were tuna, Mahi, and escolar. A limitation of these findings is that they are dependent on sample size. Most pathogen refusals were from Salmonella and thus Figure 3 has a relatively large sample 
size, which drives down the standard errors of the statistical test in mean differences between 2002 to 2006 and 2010 to 2013. This is why small changes are statistically significant in Figure 3 but not in Figures 4 and 5.

Examining FDA import refusal data is difficult due to additional limitations. The presently available data do not identify the shipments that were inspected and rejected as well as those that were inspected and not rejected. Consequently, controlling for the sample-selection bias of being inspected is not possible since the decision to inspect shipments and the number of shipments inspected is unobserved. Only the indication of a decision to refuse a shipment of unknown quantity and unknown price is observed from a sample of inspected shipments where the total shipments inspected, the volume of shipments that was inspected, the market value of shipments that was inspected and the decision to inspect are all unobserved. Lastly, the product descriptions require manual grouping which introduces a degree of measurement error when attempting to examine product-level changes. A standardized product system could reduce measurement error and facilitate port-to-plate tracking. Further, a unique identifier for foreign plants and foreign companies would facilitate linking import refusals back to specific suppliers, which could help isolate manufacturing sources of food safety violations by product. A unique identifier for the end point-of-sale would facilitate linking imported but not inspected shipments and inspected but not rejected shipments to retailers. Customers themselves could then help identify food-safety breakdowns of imported foods by product.

Such data improvements could facilitate future research on the possible and specific mechanisms, including possible foreign country specific economic and policy-relevant factors, which may further explain why the changes detected in this paper occurred. Analyzing countryproduct specific import refusals for pathogens at the product-type level in response to domestic U.S. economic conditions would extend previous research (Baylis et al. 2009 and Bovay 2016). For example, to what extent is the 12 percentage point decline in the average annual share of pathogen violations from Salmonella for shrimp products attributed to food-safety violations by specific suppliers from India, Thailand or China? Or, is this decline explained by declining U.S. demand for shrimp products?

These data improvements could also facilitate future research on the extent to which changes in import refusals following the 2007 to 2009 recession were associated with pathogen-related foodborne illness or imported food recalls in the United States. For example, to what extent is the 5.5 percentage point decline in the average annual share of pathogen violations from Listeria for cheese products associated with Listeria-related U.S. foodborne illness from imported cheese? Or, is this decline associated with fewer Listeria-related recalls for imported cheese? Such research may help estimate how changes in import refusals affect domestic foodborne illness.

Presently, coronavirus disease 2019 (COVID-19) has devastated personal lives and economic livelihoods around the world. In international trade, world merchandise trade is expected to decline between 13 and 32\% in 2020 (World Trade Organization 2020) and forecasts for agricultural goods indicate a possible decline between 6.5 and 12.7\% (Sjerven, 2020).

How will this current recession affect import refusals? It may induce foreign food suppliers to cut food-safety corners, resulting in the shipment of tainted foods. This would lead to a rise in the share of import refusals due to pathogens and a possible increase in food-safety risk from all non-inspected shipments. Or, the recession could result in business exits of foreign food suppliers. And to the extent that these exits correlate with past and persistent histories of high levels of import refusals, the shipment of tainted foods would decline. This would lead to a 
decline in the share of import refusals due to pathogens and a possible decline in food-safety risk from all non-inspected shipments.

Having a unique identifier for foreign plants and foreign companies would provide additional insights on how current changes in business conditions affect import refusals. However, to institute and maintain supplier identifiers, significant revisions to U.S. regulatory statues and international trade agreements would likely be required.

For a notable comparison, numerous changes in federal law, spanning nearly a decade, were needed to establish a Country of Origin Label which applies to muscle cuts and ground lamb, chicken, goat, wild and farm-raised fish and shellfish, perishable agricultural commodities, peanuts, pecans, ginseng, and macadamia nuts (U.S. Department of Agriculture, Agricultural Marketing Service n.d.). Hence, problematically, the state of research on import refusals remains descriptive and retrospective, and not inferential or predictive.

\section{REFERENCES}

Baylis K, Martens A, \& Nogueira L. 2009. What Drives Import Refusals? Amer. J. Agr. Econ, 91:1477-1483.

Bovay, J. 2016. FDA Refusals of Imported Food Products by Country and Category, 20052013. EIB-151, U.S. Department of Agriculture, Economic Research Service. https://www.ers.usda.gov/webdocs/publications/44066/57014_eib151.pdf?v=0

Brooks N, Buzby J, \& Regmi A. 2009. Globalization and Evolving Preferences Drive U.S. Food Import Growth. J. Food Distrib. Res., 40(1), 39-46.

Buzby J, Unnevehr L, \& Roberts D. 2008. Food Safety and Imports: An Analysis of FDA Food-Related Import Refusal Reports. EIB-39, U.S. Department of Agriculture, Economic Research Service. https://www.ers.usda.gov/publications/pub-details/?pubid=44259

Buzby J, \& Roberts D. 2010. Food Trade and Food Safety Violations: What Can We Learn from Import Refusal Data? Am. J. Agric. Econ, 93(2), 560-565.

Gale F, \& Buzby J. 2009. Imports From China and Food Safety Issues. EIB-52, U.S. Department of Agriculture, Economic Research Service. https://www.ers.usda.gov/publications/pub-details/?pubid=44392

Hoffmann S, Batz MB, \& Morris JG. 2012. Annual Cost of Illness and Quality-Adjusted Life Year Losses in the United States Due to 14 Foodborne Pathogens. J. Food Prot., 75(7), 1292-1302.

Johnson R. 2016. The Federal Food Safety System: A Primer. Washington, DC: Congressional Research Service. https://fas.org/sgp/crs/misc/RS22600.pdf

Levchenko A, Lewis LT, \& Tesar L. 2010. The Collapse of International Trade during the 2008-09 Crisis: In Search of the Smoking Gun. IMF Econ. Rev., 58, 214-253. 
Sjerven, J. 2020. “China and COVID-19 are foremost trade concerns.” Food Bus. News. https://www.foodbusinessnews.net/articles/15936-china-and-covid-19-are-foremost-tradeconcerns

U.S. Department of Agriculture, Agricultural Marketing Service. (n.d.). Country of Origin Labeling (COOL) Frequently Asked Questions. https://www.ams.usda.gov/rulesregulations/cool/questions-answers-consumers

U.S. Food and Drug Administration. 2015. Download Import Refusal Data Files. https://www.accessdata.fda.gov/scripts/importrefusals/ 